\title{
PROPORSI HASIL TANGKAPAN TRAMMEL NET PADA KEDALAMAN YANG BERBEDA DI PERAIRAN INDRAMAYU
}

\author{
Trammel net Catch Proportion at Different Depths in Indramayu's Water
}

\author{
Oleh: \\ Achmad Rizal ${ }^{1}$ dan Izza Mahdiana Apriliani ${ }^{1}$ \\ ${ }^{1}$ Departemen Perikanan, Fakultas Perikanan dan Ilmu Kelautan, Universitas Padjadjaran \\ Korespondensi: arizrzl@gmail.com
}

\begin{abstract}
ABSTRAK
Penelitian ini dilaksanakan pada bulan April sampai Mei 2017 di perairan Indramayu, Provinsi Jawa Barat. Penelitian ini bertujuan untuk mengetahui berapa besar proporsi udang hasil tangkapan utama dan by-catch dengan menggunakan alat tangkap trammel net di perairan Kabupaten Indramayu. Penelitian ini menggunakan metode survei dengan analisis deskriptif. Data yang diamati dalam penelitian ini meliputi data sekunder dan data primer. Data sekunder berupa informasi yang diperoleh dari Kantor Dinas Perikanan Kabupaten Indramayu. Pengambilan data primer dilaksanakan secara langsung melalui pengamatan di lapangan dengan mengamati hasil tangkapan yang diperoleh nelayan Desa Limbangan dan informasi tambahan dari nelayan setempat. Data primer diperoleh dengan mengikuti 15 kali trip (15 kali setting dan 15 kali hauling) pada kedalaman berbeda. Data yang diperoleh dicatat berdasarkan jenis hasil tangkapan, jumlah, ukuran dan bobot hasil tangkapan. Penelitian ini menggunakan kapal berukuran 5 GT dengan kekuatan mesin sebesar 16-23 PK. Hasil dari penelitian ini menyatakan dari total individu hasil tangkapan, alat tangkap trammel net masih selektif digunakan untuk menangkap udang pada kisaran kedalaman 5-16 m, karena jumlah individu hasil tangkapan lebih tinggi $(57,15 \%)$ dibandingkan dengan by-catch (42,84\%). Total bobot hasil tangkapan dari trammel net didominasi oleh by-catch yaitu berupa jenis ikan (82\%), dibandingkan hasil tangkapan utama yaitu jenis udang (15\%), dan discard (3\%). Proporsi jenis individu udang pada kedalaman 5-10 m didominasi oleh udang peci, krosok, dogol dan udang kipas, sedangkan pada kedalaman 11-16 m didominasi oleh udang jerbung, udang windu dan udang ronggeng.
\end{abstract}

Kata kunci: hasil tangkapan, kedalaman, perairan Indramayu, trammel net, udang

\section{ABSTRACT}

This research was conducted in April to May 2017 in the Indramayu waters, West Java Province. This study aims to know how large proportion of the major shrimp catches and by catch using fishing gear trammel net in the waters of Indramayu regency. This study used survey method with the descriptive analysis. Necessary data in this study include secondary data and primary data. Secondary data information was obtained from Indramayu District Fisheries Office. Primary data collection making observations in the field by observing results obtained catch fishermen Limbangan Village and additional information from local fishermen. Primary data is taken by following 15 trip (15 setting and 15 hauling) at different depths. The data obtained are recorded based on the kind catch, amount, size and weight of the catch. This study uses 5 GT vessels with engine power of 16-23 PK. The results of this study the individual states of the total catch, fishing gear still selective trammel net used to catch shrimp in the range of 5-16 m depth, because the amount of individuals catch is higher (57.15\%) compared to the by catch (42.84\%). The total weight of catch of trammel net was dominated by catch the form of fish (82\%), compared to the main catch that are the types of shrimp (15\%), and discard (3\%). The proportion of individual types of shrimp at the depth of $5-10 \mathrm{~m}$ is dominated by peci shrimp, 
krosok, dogol and kipas shrimp, while at the depth of 11-16 m dominated by jerbung shrimp, windu shrimp and ronggeng shrimp.

Key words: catch, depth, Indramayu's water, shrimp, trammel net

\section{PENDAHULUAN}

Kabupaten Indramayu terletak di Pantai Utara Jawa dengan panjang garis pantai $114 \mathrm{~km}$ yang memiliki potensi untuk pengembangan perikanan laut. Kabupaten ini memiliki armada penangkapan ikan yang mencapai 6.000 unit, suatu jumlah kepemilikan armada terbesar di Jawa Barat (Dinas Perikanan Provinsi Jawa Barat 2017). Sebagai daerah yang berada di wilayah pesisir pantai, kabupaten tersebut dianugerahi sumberdaya yang potensial bagi kegiatan perikanan dan kelautan, meliputi kegiatan perikanan budidaya, pengelolaan hasil perikanan dan perikanan tangkap (Rizal dkk, 2019).

Salah satu alat tangkap yang ada di Kabupaten Indramayu adalah trammel net. Trammel net sering disebut dengan jaring tiga lapis dimana dua lapis di luar (outer net) yang mempunyai mata jaring lebih besar mengapit satu lapis lembaran jaring yang ditengah (inner net) mempunyai mata jaring lebih kecil dan dipasang agak renggang (Subani dan Barus 1989). Trammel net dapat dioperasikan dengan cara dipasang menetap di dasar perairan ataupun dihanyutkan. Hasil tangkapan utama alat tangkap ini adalah jenis udang.

Udang adalah hewan kecil tak bertulang belakang (invertebrata) yang tempat hidupnya adalah di dasar lautan atau danau. Pada dasarnya udang adalah hewan pemakan segala (omnivora) yang memakan tumbuhan dan hewan kecil. Dalam berkembang biak, udang betina mampu bertelur sampai ratusan butir dan diletakkan di kaki udang betina. Setelah menetas, anak-anak udang itu berukuran sangat kecil dan seukuran plankton. Udang-udang muda ini menghabiskan waktunya dengan malayang-layang di air, namun setelah mulai tumbuh, mereka mulai tenggelam di dasar air dan mulai moulting sampai mencapai tahap udang dewasa. Udang memiliki sifat nokturnal yaitu melakukan aktifitas kehidupannya di malam hari.

Jenis alat tangkap digunakan untuk menangkap udang salah satunya trammel net. Jaring ini dioperasikan di dasar perairan, dengan hasil tangkapannya dapat dikategorikan dalam dua jenis yaitu hasil tangkapan utama (HTU) dan hasil tangkapan sampingan (by-catch). Hasil tangkapan utama merupakan hasil tangkapan yang menjadi target utama nelayan, sedangkan hasil tangkapan sampingan (by-catch) merupakan spesies yang ikut tertangkap sewaktu alat tangkap dioperasikan, biasanya bernilai ekonomis rendah, dimana sebagian diantaranya dimanfaaatkan oleh nelayan dan sebagian lainnya tidak dimanfaatkan karena berukuran kecil atau tidak memiliki nilai ekonomis.

Menurut Khaerudin (2006) hasil tangkapan utama trammel net adalah jenis udang dan by-catch berupa ikan-ikan demersal seperti ikan pepetek (Leiognathus sp.), gulama (Pseudosciena sp.) beloso (Saurida tumbil), tenggiri (Scomberomorus sp.) dan lain-lain. Sebagian besar masyarakat di Desa Limbangan Kabupaten Indramayu bekerjasebagai nelayan dengan mengoperasikan berbagai jenis alat tangkap dan yang paling dominan adalah trammel net. Jaring ini termasuk jenis jaring penyangkut karena ikan atau udang yang tertangkap disebabkan tersangkut atau terjerat di mata jaring.

Ketersediaan udang pada suatu wilayah akan berubah seiring dengan perubahan lingkungan, yang menyebabkan udang akan memilih tempat yang sesuai dengan kondisi lingkungannya. Salah satu faktor yang mempengaruhi ketersediaan udang di suatu perairan adalah kedalaman. Kedalaman suatu perairan berpengaruh terhadap intensitas cahaya. Semakin dalam suatu perairan intensitas cahaya semakin berkurang, begitu juga sebaliknya. Kedalaman juga menunjang sifat keaktifan udang di perairan (Powers dan Bliss 1983). 
Permintaan produk bahan baku udang sangat dibutuhkan hingga saat ini yaitu sebagai pelengkap kebutuhan protein dan menguatnya perekonomian di negara importir. Udang memiliki harga yang baik dan merupakan salah satu komoditas unggulan yang mempunyai nilai ekonomis tinggi sebagai salah satu penyumbang pendapatan nelayan dan penyumbang devisa negara yang cukup besar. Sumberdaya udang harus dikelola dengan baik, sehingga dapat dipanen terus menerus dan memberikan kontribusi kesejahteraan nelayan yang berkelanjutan (Rizal, 2018). Guna mencapai tujuan tersebut sangat diperlukan informasi tentang proporsi tangkap jaring trammel net sebagai dasar penentuan kebijakan dalam pemanfaatan sumberdaya udang secara berkesinambungan.

\section{METODE PENELITIAN}

Penelitian ini dilaksanakan di Perairan Desa Limbangan, Kabupaten Indramayu, Provinsi Jawa Barat. Penelitian dilaksanakan pada bulan April-Mei 2017. Penelitian ini menggunakan metode survei dengan analisis deskriptif yang meliputi data primer dan data sekunder. Pengambilan data primer dilakukan secara langsung melalui pengamatan di lapangan dengan mengamati hasil tangkapan yang diperoleh nelayan Desa Limbangan dan informasi tambahan dari nelayan setempat. Data sekunder berupa informasi yang diperoleh dari Kantor Dinas Perikanan Kabupaten Indramayu. Adapun pengambilan data ini dimaksudkan untuk mengetahui kondisi umum perikanan, armada penangkapan ikan perairan Indramayu, Kabupaten Indramayu. Operasi penangkapan udang dilakukan dengan menggunakan perahu sebanyak 15 kali trip, satu trip berlangsung satu kali dalam sehari. Pengoperasian trammel net dimulai pada pukul 05.00 wib dengan menyiapkan perbekalan, pemeriksaan kondisi kapal, mesin dan alat tangkap serta bahan bakar.

Penentuan stasiun penelitian (daerah penangkapan) dilakukan berdasarkan pengamatan nelayan setempat. Jarak lokasi penelitian yang terdekat dari pantai kurang lebih 1 mil.Secara rinci pengukuran kedalaman perairan pada masing-masing stasiun dilakukan dengan mengukur langsung kedalaman perairan menggunakan pemberat (bandul berbahan besi) yang diberi tali, lalu ditenggelamkan hingga mencapai dasar perairan. Panjang tali yang tenggelam hingga dasar perairan diukur, hasil pengukuran kedalaman pada setiap stasiun penangkapan dicatat.

Data yang dikumpulkan dalam penelitian ini adalah data primer. Pengumpulan data dilakukan melalui pengamatan/observasi langsung serta studi pustaka. Data primer diperoleh dengan mengikuti 15 kali trip (15 kali setting dan 15 kali hauling) sebagai pengulangan pada perlakuan kedalaman berbeda yaitu 5-10 m dan 11-16 m. Data yang diperoleh dicatat berdasarkan:

a) Jenis hasil tangkapan,

b) Jumlah (individu),

c) Ukuran $(\mathrm{cm})$

d) Bobot (gr),

Udang dan hasil tangkapan sampingan diidentifikasi berdasarkan metode yang digunakan oleh Moosa dan Aswandy (1984). Hasil tangkapan udang dan diversitas hasil tangkapan sampingan dengan menggunakan alat tangkap trammel net diuji dengan menggunakan uji t-student (Steel dan Torrie 1995), jumlah hauling dianggap sebagai ulangan (15 hari).

Kriteria uji dihitung menurut persamaan:

Keterangan:

$$
t=\frac{\overline{Y 1}-\overline{Y 2}}{\sqrt{S / n}}
$$

t : Simpangan nilai tengah

$\overline{Y 1}$ : Nilai rata-rata proporsi hasil tangkapan pada kedalaman perairan 5-10 m

$\overline{Y 2}$ : Nilai rata-rata proporsi hasil tangkapan pada kedalaman 11-16 m

s : Simpangan baku

$\mathrm{n} \quad$ : Jumlah total ulangan (15 kali) 


\section{HASIL DAN PEMBAHASAN}

Desa Limbangan terletak di bagian timur pantai Kabupaten Indramayu yang merupakan daerah penghasil ikan laut dan pesisir pantai. Jarak Desa Limbangan dari Kabupaten Indramayu kurang lebih 9,8 kilometer dan dapat ditempuh selama 45 menit perjalanan dengan menggunakan kendaraan bus maupun motor. Sarana dan prasarana perjalanan ke Desa Limbangan cukup baik, karena daerah tersebut dekat dengan daerah pariwisata. Di desa tersebut terdapat pangkalan pendaratan ikan (PPI) dan tempat pelelangan ikan (TPI) sekaligus berfungsi sebagai tempat penimbangan, pendataan hasil tangkapan, termasuk pembayaran pajak. Tidak semua hasil tangkapan di data di TPI, karena sebagian nelayan langsung menjual hasil kepada pengumpul.

Suhu air di perairan selama penelitian (April-Mei) relatif hangat kisaran $26,3^{\circ} \mathrm{C}-31^{\circ} \mathrm{C}$. Menurut nelayan setempat jarak daerah penangkapan udang berkisar 8-50 mil dari pantai. Daerah ini merupakan salah satu faktor yang disenangi udang karena substratnya berbahan dasar lumpur. Disolved oxygen (DO) yang terkandung pada daerah penelitian sekitar 22-41 mg/L. Kadar salinitas pada perairan penelitian yaitu kisaran 28,40-38 ppt, dengan kecerahan perairan sekitar 1,7-2,5 meter. Kondisi cuaca selama penelitian yaitu sedikit berawan, cerah dan berangin. Kuatnya angin berhembus menyebabkan terbentuknya ombak dengan tinggi sekitar 1-3,5 meter. Hal ini sebagai faktor penghambat pergerakan kapal penelitian menuju daerah penangkapan.

Terdapat 7 (tujuh) spesies udang tertangkap yang masuk kedalam hasil tangkapan utama (HTU), sedangkan by-catch ada 21 jenis ikan, 2 jenis krustacea, 2 jenis sotong, dan 1 jenis dikelompokkan kedalam kekerangan (Tabel 1).

Total bobot hasil tangkapan dari jaring trammel net selama mengikuti trip sebanyak $28 \mathrm{~kg}$, terdiri dari hasil tangkapan udang (HTU) sebanyak 4,18 kg (15\%), hasil tangkap sampingan (HTS) yang dimanfaatkan sebanyak 22,93 kg (82\%) dan yang dibuang ke laut (discard) sebanyak 0,88 $\mathrm{kg}$ (3\%) (Gambar 1).

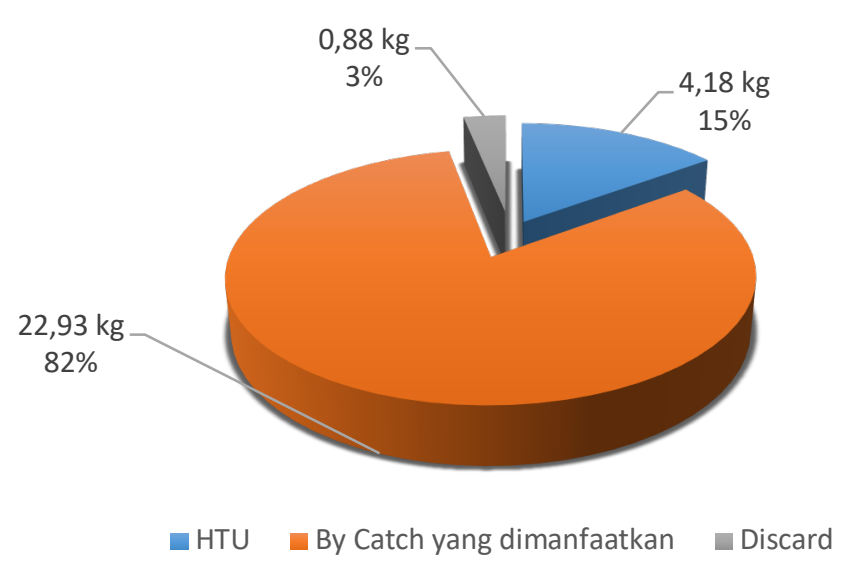

Gambar 1 Komposisi total bobot hasil tangkapan jaring trammel net 
Tabel 1 Jenis hasil tangkapan total jaring trammel net selama penelitian

\begin{tabular}{|c|c|c|c|c|}
\hline No & Kelompok & Nama daerah & Nama latin & Keterangan \\
\hline 1 & Krustase & Kepiting & Scylla serrata & Dibuang \\
\hline 2 & & Rajungan & Portunus sp. & Dimanfaatkan \\
\hline 3 & & Udang Dogol & Metapenaeus ensis & Dimanfaatkan \\
\hline 4 & & Udang Kipas & Tenus orientalis & Dimanfaatkan \\
\hline 5 & & Udang Krosok & Parapenaeopsis sculptitis & Dimanfaatkan \\
\hline 6 & & Udang Jerbung & Penaeus merguiensis & Dimanfaatkan \\
\hline 7 & & Udang Peci & Penaeus indicus & Dimanfaatkan \\
\hline 8 & & Udang Ronggeng & Lysiosquilla maculata & Dimanfaatkan \\
\hline 9 & & Udang Windu & Penaeus monodon & Dimanfaatkan \\
\hline 10 & Ikan & Balak & Synodus saurus & Dimanfaatkan \\
\hline 11 & & Bawal & Stromateus cinereus & Dimanfaatkan \\
\hline 12 & & Belanak & Mugil dossumieri & Dimanfaatkan \\
\hline 13 & & Beloso & Saurida tumbil & Dimanfaatkan \\
\hline 14 & & Bilis & Lycengraulis grossidens & Dimanfaatkan \\
\hline 15 & & Buntal & Tetraodon nigroviridis & Dibuang \\
\hline 16 & & Duri & Hemibagrus nemurus & Dimanfaatkan \\
\hline 17 & & Gerong/Kuwe & Caranx ignobilis & Dimanfaatkan \\
\hline 18 & & Gulamah & Pseudocienna amovensis & Dimanfaatkan \\
\hline 19 & & Kakap merah & Lutjanus campechanus & Dimanfaatkan \\
\hline 20 & & Kembung & Rastrelliger sp. & Dimanfaatkan \\
\hline 21 & & Kerapu & Epinephelus sp. & Dimanfaatkan \\
\hline 22 & & Lajan (kurau) & Eleutheronema sp. & Dimanfaatkan \\
\hline 23 & & Layur & Trichiurus lepturus & Dimanfaatkan \\
\hline 24 & & Lidah & Cynoglossus lingua & Dimanfaatkan \\
\hline 25 & & Manyung & Arius thalassinus & Dimanfaatkan \\
\hline 26 & & Pari & Dasyatis sp. & Dimanfaatkan \\
\hline 27 & & Pepetek & Leiognathus equulus & Dimanfaatkan \\
\hline 28 & & Tetet & Johnius belangerii & Dimanfaatkan \\
\hline 29 & & Sebelah & Psettodes erumeri & Dimanfaatkan \\
\hline 30 & Moluska & Cumi & Loligo spp. & Dimanfaatkan \\
\hline 31 & & Sotong & Sepia sp. & Dimanfaatkan \\
\hline 32 & Coelenterata & Ubur-ubur & Cassiopeia & Dibuang \\
\hline 33 & Lain-lain & Kekerangan & Murex sp., dll & Dibuang \\
\hline
\end{tabular}

Meskipun HTU dan by-catch dalam bobot menunjukkan perbedaan, tetapi proporsi total individu HTU dan by catch pada kedalaman 5-10 m tidak memiliki perbedaan yang terlalu besar. Proporsi total individu HTU pada kedalaman 5-10 m adalah 55,82\% dan by-catch adalah sebesar $44,18 \%$. Hal ini berarti bahwa alat tangkap trammel net masih termasuk selektif, dapat dilihat dari besar presentasi proporsi HTU dibanding by-catch (Tabel 2).

Tabel 2. Total individu HTU dan by-catch (ekor)

\begin{tabular}{lccc}
\hline \multicolumn{1}{c}{ Kedalaman Perairan $(\mathrm{m})$} & HTU & by-catch & Total \\
\hline A (5-10) & 2728 & 2159 & 4887 \\
& $(55,82 \%)$ & $(44,18 \%)$ & \\
\hline B (11-16) & 2296 & 1607 & 3903 \\
& $(58,83 \%)$ & $(41,17 \%)$ & \\
\hline \multirow{2}{*}{ Total } & 5024 & 3766 & 8790 \\
& $(57,15 \%)$ & $(42,84 \%)$ & \\
\hline
\end{tabular}


Proporsi total individu HTU dan HTS pada kedalaman 11-16 m dari hasil penelitian ternyata tidak jauh berbeda dengan kedalaman 5-10 m. Proporsi total individu HTU pada kedalaman 11-16 m adalah sebesar 58,83\% dan by-catch sebesar 41,17 \%. Hal ini menjelaskan bahwa alat tangkap trammel net di Perairan Limbangan terhadap total individu masih selektif digunakan, karena proporsi by-catch tidak lebih dari 50\% dari hasil tangkapan keseluruhan.

Jaring trammel net memberikan kontribusi hasil tangkap sampingan yang lebih besar tetapi dapat menghasilkan produk udang tiga kali lipat bila dibandingkan dengan alat tangkap lainnya (BPPI 2007). Hal ini disebabkan karena jaring trammel net merupakan alat yang paling efektif dan selektif untuk menangkap udang.

Konstruksi jaring trammel net memiliki jaring sebanyak 3 (tiga) lapis dengan lapisan luar memiliki mess size lebih besar daripada jaring lapisan tengahnya. Ukuran mata jaring yang relatif kecil menyebabkan banyak organisme laut lain yang ikut tertangkap termasuk ikan dalam berbagai ukuran. Rata-rata perbandingan berat antara hasil tangkapan udang dan hasil tangkap sampingan selama penelitian sebesar 1:6. Kecilnya perbandingan udang dan by catch dapat disebabkan karena:

1) Alat tangkap jaring trammel net memiliki sifat pasif yaitu tidak mengejar target tangkapan tetapi memanfaatkan arah arus laut, sehingga udang maupun ikan yang berenang melawan arus atau terbawa arus akan turut tertangkap oleh jaring penangkapan;

2) Perairan tempat penelitian adalah perairan dangkal dengan kedalaman 5-16 m kondisi ini menyebabkan sebagian besar kolom perairan tertutupi dengan jaring, ditandai dengan tertangkapnya jenis ikan pelagis dan hewan dasar perairan;

3) Perairan yang dangkal merupakan tempat ikan mencari makan (feeding ground), daerah pemijahan (spawning ground) dan daerah asuhan (nursery ground), sehingga banyak ikan-ikan muda (berukuran kecil) yang ikut tertangkap.

Hasil penelitan menunjukkan bahwa, berdasarkan kedalaman perairan penelitian (5-10 $\mathrm{m}$ dan 11-16 m) terdapat 7 (tujuh) jenis udang, yaitu udang dogol (Metapenaeus ensis), udang kipas (Tenus orientalis), udang krosok (Parapenaeopsis sculptilis), udang jerbung (Penaeus merguiensis), udang peci (Penaeus indicus), udang ronggeng (Lysiosquilla maculate) dan udang windu (Penaeus monodon). Pada kedalaman 5-10 m udang yang paling banyak tertangkap adalah udang peci (Penaeus indicus), sedangkan pada kedalaman 11-16 m udang yang paling banyak tertangkap adalah udang jerbung (Penaeus merguiensis) (Tabel 3).

Tabel 3. Komposisi jenis udang yang tertangkap (ekor)

\begin{tabular}{|c|c|c|c|c|c|c|c|c|c|}
\hline $\begin{array}{c}\text { Kedalaman } \\
\text { Perairan }(\mathrm{m})\end{array}$ & $\begin{array}{c}\text { Jerbun } \\
\mathrm{g}\end{array}$ & $\begin{array}{l}\text { Wind } \\
\mathrm{u}\end{array}$ & Peci & Krosok & Dogol & Kipas & $\begin{array}{c}\text { Rongge } \\
\text { ng }\end{array}$ & Total & $\begin{array}{c}\text { Rata- } \\
\text { rata/ } \\
\text { Trip }\end{array}$ \\
\hline$A(5-10)$ & 68 & 101 & 1531 & 220 & 164 & 407 & 237 & 2728 & 181,90 \\
\hline B (11-16) & 689 & 359 & 330 & 117 & 73 & 331 & 397 & 2296 & 153,06 \\
\hline Total (ekor) & 757 & 460 & 1861 & 337 & 237 & 738 & 634 & 5024 & 334,93 \\
\hline
\end{tabular}

Jumlah keseluruhan udang yang tertangkap selama penelitian dengan menggunakan 5 piece jaring trammel net yaitu sebanyak 5024 ekor, yang terdiri dari udang jerbung sebanyak 757 ekor (15,07\%), udang windu sebanyak 460 ekor (9,15\%), udang peci sebanyak 1861 ekor (37,04\%), udang krosok sebanyak 337 ekor (6,70\%), udang dogol sebanyak 237 ekor (4,78\%), udang kipas sebanyak 738 ekor (14,64\%) dan udang ronggeng sebanyak 634 ekor (12,62\%) (Tabel 3).

Jumlah udang peci tertangkap pada kedalaman 5-10 m adalah sebanyak 1531 ekor dan pada kedalaman 11-16 m adalah sebanyak 330 ekor. Hal ini berbeda dengan jumlah udang jerbung yang banyak tertangkap pada kedalaman 11-16 m yaitu sebanyak 689 ekor sedangkan pada kedalaman 5-10 m hanya 68 ekor (Gambar 2). 


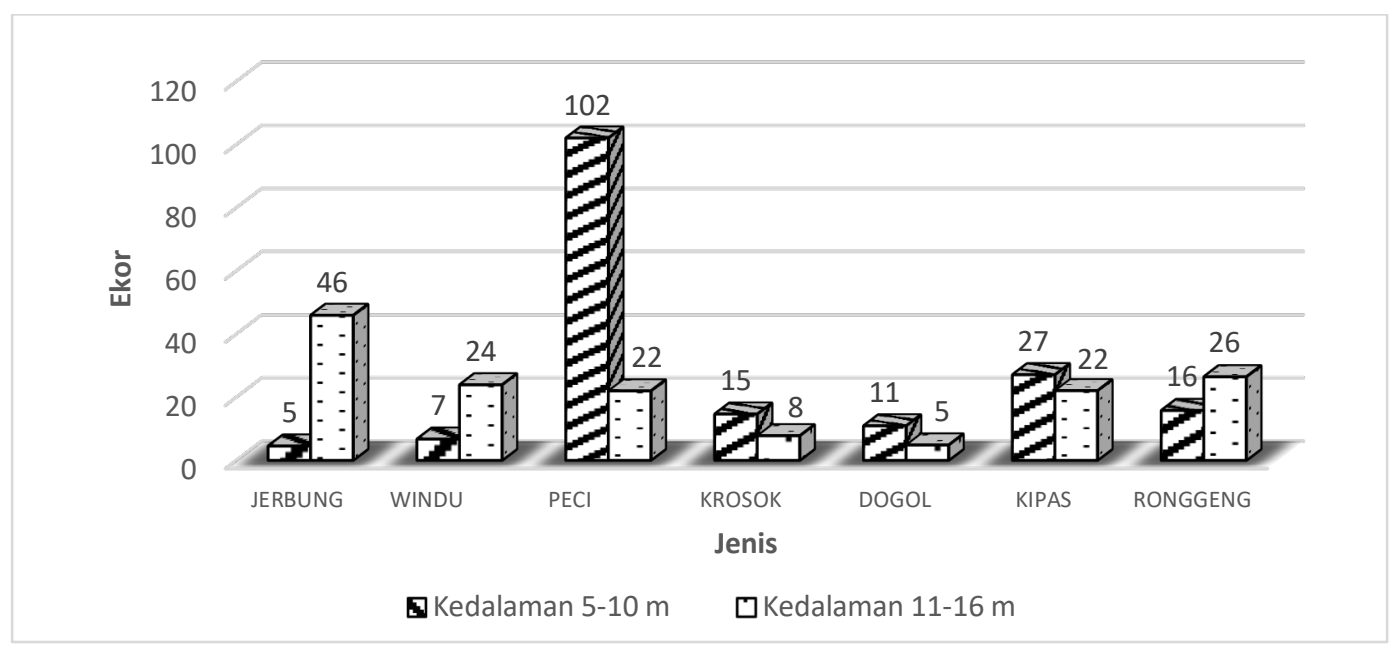

Gambar 2. Komposisi rata-rata jenis udang pada kedalaman 5-10 m dan 11-16 m

Walaupun termasuk genus yang sama (penaeus), tetapi udang peci dan udang jerbung memiliki tempat hidup pada kedalaman yang berbeda. Menurut Sunarto (2002) udang peci dan udang jerbung memiliki kesamaan dalam faktor musim dan perilaku. Dalam kesesuaian habitat juga memiliki kesamaan, yaitu substrat mengandung lumpur bercampur sedikit pasir.

Menurut Naamin (1987) udang peci memiliki kesukaan hidup pada perairan yang dangkal berbeda dengan udang jerbung lebih menyukai dasar perairan yang lebih landai. Perbedaan perairan tersebut dipengaruhi oleh kedalaman dan kualitas air pada suatu perairan. Menurut Martosoedarmo dan Ranoemihardjo (1980) suhu dan salinitas merupakan faktor yang paling berpengaruh terhadap kelimpahan dan keberlangsungan hidup udang. Pernyataan yang sama dijelaskan oleh Rothschild dan Brunenmeister (1984) bahwa temperatur dan salinitas merupakan faktor dominan yang mempengaruhi daya tahan hidup (survival) dan pertumbuhan udang penaeus yaitu berkisar 25-33 ppt.

Hasil analisis t-student terhadap perbedaan rata-rata jumlah individu udang hasil tangkapan (Tabel 4) menggunakan jaring trammel net pada kedalaman 5-10 m dan 11-16 m ternyata menunjukkan hasil yang berbeda (signifikan). Pada kedalaman 5-10 m udang yang dominan tertangkap adalah udang peci, udang krosok, udang dogol dan udang kipas, sedangkan pada kedalaman 11-16 m adalah udang jerbung, udang windu dan udang ronggeng. Hal ini disebabkan oleh tiap jenis individu udang memiliki ciri dan sifat, serta kesukaan terhadap habitatnya masing-masing. Hal ini juga dipengaruhi oleh ketersediaan makanan pada habitatnya.

Tabel 4. Beda dua rata-rata jumlah individu udang pada kedalaman berbeda

\begin{tabular}{cccc}
\hline No. & Kedalaman $(\mathrm{m})$ & $\begin{array}{c}\text { Rata-rata Jumlah Udang } \\
\text { (ekor/Trip) }\end{array}$ & Signifikan \\
\hline 1. & $5-10$ & 181,9 & $\mathrm{a}$ \\
2. & $11-16$ & 153,06 & $\mathrm{~b}$ \\
\hline
\end{tabular}

Keterangan: Rata-rata yang diikuti huruf yang berbeda menunjukkan adanya perbedaan antara dua kedalaman dengan uji $\neg$ t-student $5 \%$.

Berdasarkan Tabel 5 dari hasil tangkapan selama penelitian, dapat dinyatakan bahwa pemasangan jaring trammel net pada kedalaman yang berbeda memberikan pengaruh terhadap bobot hasil tangkapan udang. Hasil ini sesuai dengan Suman et al. (1993) bahwa daerah penangkapan udang pada umumnya ada pada kedalaman 3-20 m. Hal ini karena daerah tersebut merupakan habitat dari udang, dengan kondisi perairan subur yang menyediakan banyak makanan untuk kelangsungan hidup udang (Odum 1998). Hal ini dijelaskan oleh Subani dan Barus (1989), udang banyak terdapat pada 
kedalaman 10-15 m, walaupun pada saat tertentu melakukan migrasi ke daerah yang dangkal atau ke daerah yang lebih dalam untuk mencari makanan atau untuk melakukan pemijahan.

Tabel 5. Rata-rata bobot udang yang tertangkap (gram)

\begin{tabular}{lccccccccc}
\hline $\begin{array}{c}\text { Kedalaman } \\
\text { Perairan }(\mathrm{m})\end{array}$ & $\begin{array}{c}\text { Jerbun } \\
\mathrm{g}\end{array}$ & $\begin{array}{c}\text { Wind } \\
\mathrm{u}\end{array}$ & Peci & $\begin{array}{c}\text { Kroso } \\
\mathrm{k}\end{array}$ & Dogol & Kipas & $\begin{array}{c}\text { Rongge } \\
\mathrm{ng}\end{array}$ & Total & $\begin{array}{c}\text { Rata- } \\
\text { rata/ } \\
\text { Trip }\end{array}$ \\
\hline A (5-10) & 26,67 & 2,00 & 21,07 & 2,25 & 2,10 & 19,73 & 27,73 & 101,55 & 6,77 \\
$\mathrm{~B}(11-16)$ & 117,40 & 19,27 & 25,00 & 2,30 & 4,33 & 37,93 & 15,18 & 221,41 & 14,76 \\
\hline Total (ekor) & 144,07 & 21,27 & 46,07 & 4,55 & 6,43 & 57,66 & 42,91 & 322,96 & 10,76 \\
\hline
\end{tabular}

Berdasarkan Tabel 5 dari hasil tangkapan selama penelitian, dapat dinyatakan bahwa pemasangan jaring trammel net pada kedalaman yang berbeda memberikan pengaruh terhadap bobot hasil tangkapan udang. Hasil ini sesuai dengan Suman et al. (1993) bahwa daerah penangkapan udang pada umumnya ada pada kedalaman 3-20 m. Hal ini karena daerah tersebut merupakan habitat dari udang, dengan kondisi perairan subur yang menyediakan banyak makanan untuk kelangsungan hidup udang (Odum 1998). Hal ini dijelaskan oleh Subani dan Barus (1989), udang banyak terdapat pada kedalaman 10-15 m, walaupun pada saat tertentu melakukan migrasi ke daerah yang dangkal atau ke daerah yang lebih dalam untuk mencari makanan atau untuk melakukan pemijahan.

Komposisi rata-rata bobot hasil tangkapan pada kedalaman 11-16 m ternyata jauh berbeda dengan kedalaman 5-11 m. Pada kedalaman 5-10 m jenis udang yang memiliki rata-rata bobot terbesar adalah udang ronggeng (Gambar 3). Setiap jenis udang memiliki perbedaan bobot yang berbeda. Bobot pada hasil tangkapan udang dipengaruhi oleh ukuran, umur dan populasi siklus hidup udang. Suatu kelompok udang yang telah mencapai umur tertentu pada suatu daerah akan bermigrasi massal ke daerah yang lebih cocok, sehingga suatu kelompok udang umumnya mempunyai ukuran keseragaman.

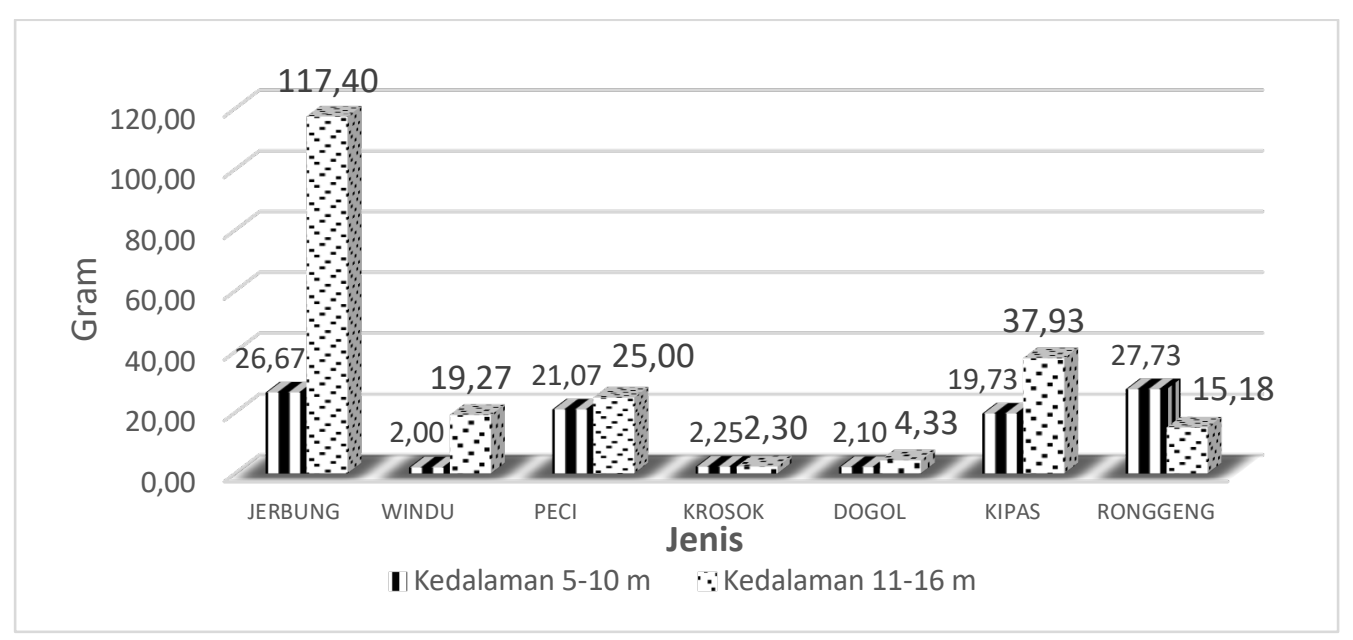

Gambar 3. Komposisi rata-rata bobot jenis udang kedalaman 5-10 m dan 11-16 m

Hasil analisis statistik t-student data bobot rata-rata hasil tangkapan pada 2 (dua) kisaran kedalaman (Tabel 6) ternyata memberikan hasil yang berbeda nyata. Hal ini diduga karena selama penelitan berlangsung terjadi siklus musim tahunan yang waktunya bersamaan, dimana udang yang berukuran besar berada di perairan yang lebih dalam (11-16 m).

Menurut Riyanto (2005) musim barat menyebabkan banyak aliran air sungai yang membawa unsur hara dan makanan. Hal ini dimanfaatkan oleh berbagai moluska, echinodermata dan hewanhewan lainnya sebagai sumber makanan udang. Sehingga kelompok udang akan melakukan migrasi ke daerah uang banyak mengandung makanan. Juga disebabkan penyebaran udang pada daerah penelitian 
tidak seragam. Mungkin kondisi cuaca lokasi penelitian berangin dan berombak menyebabkan penyebaran udang pada perairan meluas.

Tabel 6. Beda dua rata-rata bobot individu udang pada kedalaman berbeda

\begin{tabular}{cccc}
\hline No. & Kedalaman $(\mathrm{m})$ & $\begin{array}{c}\text { Rata-rata Bobot Udang } \\
\text { (ekor/Trip) }\end{array}$ & Signifikan \\
\hline 1 & $5-10$ & 6,77 & $\mathrm{~b}$ \\
2 & $11-16$ & 14,76 & $\mathrm{a}$ \\
\hline
\end{tabular}

Keterangan: Rata-rata yang diikuti huruf yang berbeda menunjukkan adanya perbedaan antara dua kedalaman dengan uji t-student 5\%.

Hasil tangkapan udang selama penelitian (30 kali hauling dalam 15 trip) telah diidentifikasi sebanyak 7 (tujuh) spesies udang. Jumlah dan bobot hasil tangkapan udang memiliki proporsi yang berbeda pada kisaran kedalaman 5-10 m dan 11-16 $\mathrm{m}$.

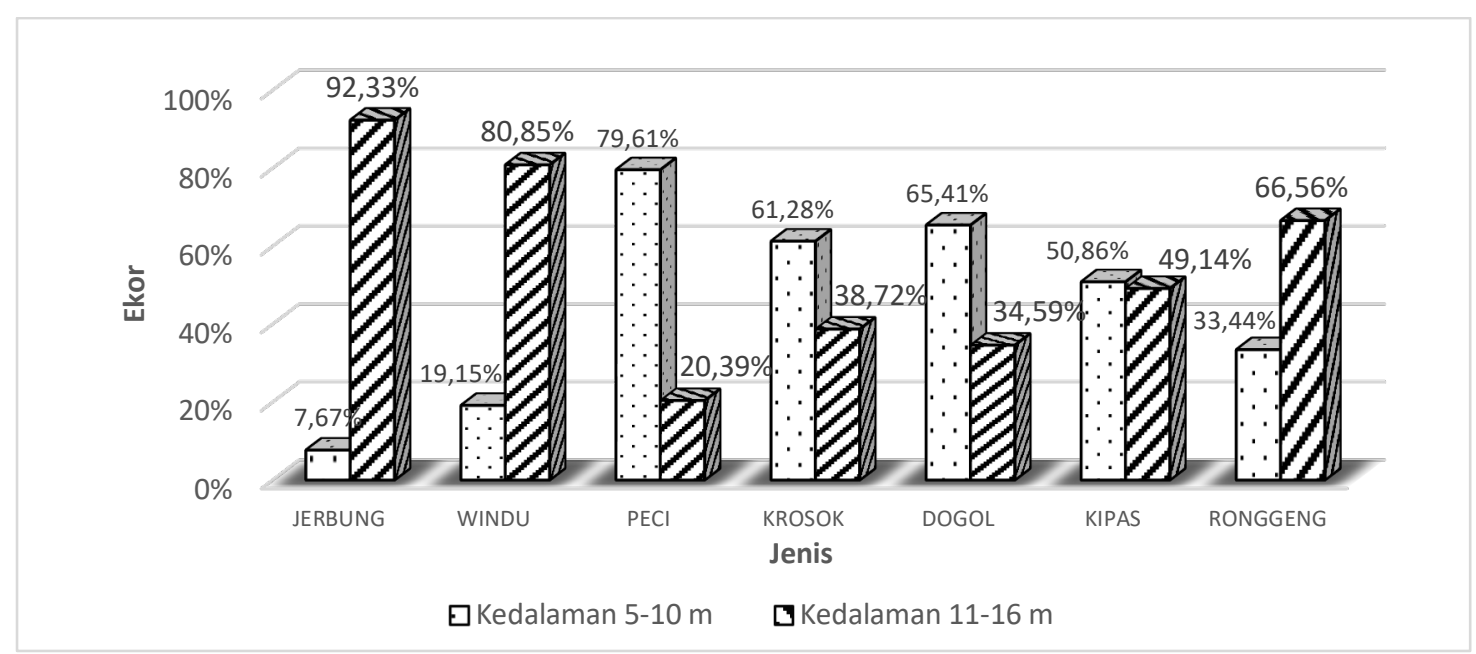

Gambar 4. Proporsi individu masing-masing jenis udang kedalaman 5-10 m dan 11-16 m

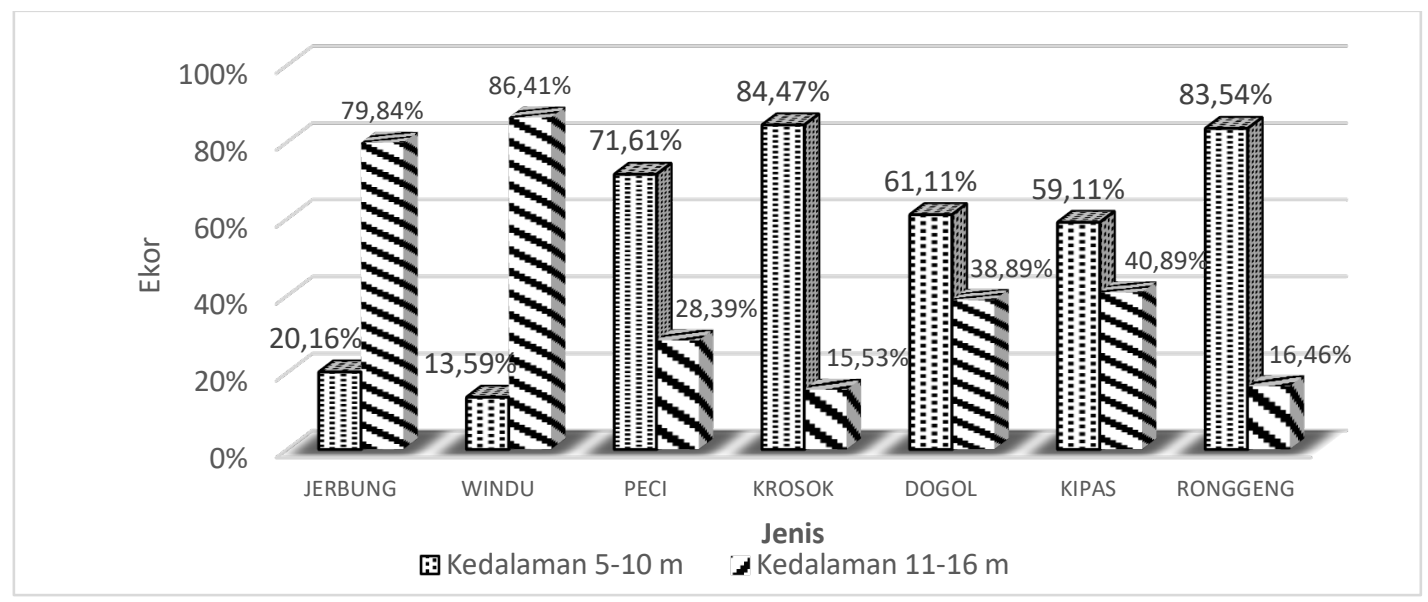

Gambar 5. Proporsi bobot individu udang kedalaman 5-10 m dan 11-16 m

Terdapat perbedaan proporsi hasil tangkapan pada kedalaman 5-10 m dan 11-16m. Hasil pengolahan data, proporsi jenis (Gambar 4) dan bobot (Gambar 5) udang jerbung pada kedalaman 5-10 m adalah 7,67\% dan 20,16\%, sedangkan pada kedalaman 11-16 m sebesar 92,33\% dan 79,84\%. 
Perbedaan yang cukup signifikan ini menjelaskan bahwa udang jerbung lebih menyukai hidup di habitat perairan yang dalam.

Tingginya proporsi udang jerbung ini dipengaruhi oleh musim, cuaca, iklim dan metode penangkapan udang yang digunakan oleh nelayan. Pengoperasian penangkapan udang yang dilakukan pada siang hari sebagai faktor banyaknya volume tangkapan udang jerbung. Hal ini sesuai dengan Naamin (1984) hasil tangkapan udang jerbung pada waktu siang hari lebih baik/lebih tinggi daripada waktu malam hari. Selama penelitian, udang jerbung yang diperoleh rata-rata memiliki ukuran yang besar.

Perbedaan ukuran dan bobot udang juga di pengaruhi oleh kedalaman. Fase hidup udang jerbung pada saat penangkapan diduga pada tahap fase dewasa. Pada fase ini udang akan ber-ruaya menuju perairan yang lebih dalam. Udang dewasa bertelur dan menetaskan larva di laut kemudian larva berkembang di muara sungai hingga akhirnya udang remaja berkembang menjadi udang dewasa dan matang telur serta kemudian memijah di laut. Udang dewasa lebih menyukai daerah yang memiliki salinitas tinggi dibandingkan dengan udang pada fase berkembang. Menurut del Mundo (2000) udang jerbung mempunyai toleransi salinitas yang tinggi hingga $45 \mathrm{ppt}$, juvenilnya hidup di estuari dan dewasanya di perairan laut (Holthuis 1980).

Dari hasil penelitian, proporsi jenis (Gambar 4) dan bobot (Gambar 5) udang windu memiliki perbedaan yang cukup besar pada kisaran kedalaman. Pada kedalaman 5-10 m proporsinya itu sebesar 19,15\% dan 13,59 \%, sedangkan kedalaman 11-16 m sebesar 80,85\% dan 86,41 \%. Proporsi terbesar hasil tangkapan udang windu yaitu pada kedalaman 11-16 m. Hal ini disebabkan oleh, pada saat penangkapan udang windu dominan pada kedalaman 11-16 m. Adanya dominasi udang pada kedalaman 11-16 m diduga karena, populasi udang windu dewasa melakukan migrasi.

Daur hidup udang windu dewasa akan memijah di laut lepas, sedangkan udang muda (juvenil) bermigrasi ke daerah pantai. Menurut Riyanto (2005) di wilayah Indonesia barat, puncak musim benur udang jatuh pada bulan November hingga Februari dan Maret sampai awal Juni. Penangkapan dilakukan yaitu pada saat penelitian dilaksanakan yaitu pada bulan Maret-April. Hal ini menyebabkan udang windu dominan tertangkap ada kedalaman 11-16 m dibanding kedalaman 5-10 m. Fase umur udang windu pada daerah pesisir di perkirakan dominan masih berukuran kecil yaitu pada fase stadia juvenil, sehingga pada saat pengoperasian alat tangkap trammel net udang banyak yang lolos karena ukuran udang lebih kecil daripada ukuran mesh size jaring.

Pada proporsi jenis (Gambar 4) dan bobot (Gambar 5) udang peci memiliki perbedaan yang sama dengan udang jerbung. Pada kedalaman 11-16 m hasil tangkapan udang didominasi oleh udang jerbung, sedangkan kedalaman 5-10 m didominasi oleh udang peci. Volume penangkapan dan bobot udang peci terbesar yaitu pada daerah pesisir pantai kisaran kedalaman 5-10 m. Substrat perairan dikedalaman 5$10 \mathrm{~m}$ adalah daerah berlumpur. Diduga substrat tersebut berasal dari daratan yang terbawa oleh arus air dari daratan tertinggi hingga ke perairan laut. Udang peci memiliki daya penyesuaian yang tinggi terhadap tipe dasar perairan, tetapi lebih menyukai dasar perairan lumpur liat berpasir (Pratiwi, 2008). Menurut Naamin (1984) udang peci tersebar hampir di seluruh perairan laut yang relatif dangkal.

Pada kedalaman 5-10 m proporsi udang krosok sebesar 61,28\% berbeda pada kedalaman 11-16 m yaitu sebesar 38,72\% (Gambar 4). Udang krosok menyukai daerah yang salinitasnya tidak terlalu tinggi. Menurut Holthuis (1980); Del Mundo (2000) menyatakan bahwa udang dogol dan udang krosok mempunyai kemampuan yang baik dalam menyesuai diri terhadap fluktuasi salinitas yang ada di perairan muara, bahkan udang dogol dan krosok mampu hidup di perairan tawar. Dari pengamatan proporsi bobot udang krosok (Gambar 5), menjelaskan bahwa bobot udang krosok lebih besar tertangkap pada kedalaman 5-10 m. Diperkirakan populasi udang krosok yang tertangkap memiliki ukuran tubuh yang sama besar yaitu pada fase dewasa. 
Perbedaan proporsi udang dogol menunjukkan bahwa hasil tangkapan udang dogol pada kedalaman 5-10 m sebesar 65,41 \% lebih kecil daripada kedalaman 11-16 m sebesar 34,59\% (Gambar 4). Besarnya hasil tangkapan udang dogol pada kedalaman 5-10 m, karena udang dogol lebih mendominasikan dirinya pada daerah mendekati pantai.

Jika dilihat proporsi bobot individu udang, spesies individu udang dogol yang tertangkap lebih dominan pada kedalaman 5-10 m (Gambar 5). Hal ini menunjukkan, udang dogol lebih menyukai daerah perairan dekat daratan. Menurut Penn (1981) habitat yang disukai udang dogol adalah dasar laut yang lumer, biasanya terdiri dari campuran lumpur dan pasir. Udang dogol menyenangi daerah yang terjadi pencampuran air sungai dengan air laut (estuaria), karena di daerah ini banyak terdapat makanan serta zat-zat hara. Umur udang dogol pada saat penangkapan berada pada fase juvenile menuju dewasa.

Berbeda dengan udang dogol, proporsi udang kipas tidak jauh berbeda pada kisaran kedalaman berbeda. Pada kedalaman 5-10 m proporsi udang kipas yaitu sebesar 50,86\% sedangkan pada kedalaman 11-16 m sebesar 49,14\% (Gambar 4). Hasil tangkapan udang kipas pada kisaran kedalaman tersebut memiliki selisih sebesar 1,72\%. Dari proporsi bobot udang kipas juga tidak menunjukkan perbedaan yang signifikan (Gambar 5). Hal ini menyatakan bahwa penyebaran udang kipas pada perairan indramayu merata. Menurut Pratiwi (2011) bahwa udang kipas hidup pada kedalaman 5-60 m, substrat pasir dengan butiran yang agak kasar. Udang kipas memiliki kemampuan yang unik untuk dapat beradaptasi dengan lingkungannya, dapat berenang dengan jarak tempuh yang jauh dan membenamkan diri dalam sedimen (substrat lumpur atau pasir).

Udang ronggeng memiliki perbedaan proporsi pada kisaran kedalaman. Pada kedalaman 5-10 m proporsinya sebesar 33,44\%, sedangkan pada kedalaman 11-16 m yaitu sebesar 66,56\% (Gambar 4). Udang ronggeng menyukai habitat didaerah intertidal dengan hamparan berlumpur (mudflat). Hasil pengukuran beberapa parameter kualitas perairan pada habitat udang ronggeng terdiri dari salinitas pada kisaran 5-10 m dan 11-16 m yaitu sekitar 7,1-7,8 ppt dan suhu berada pada kisaran 28,5-31ㅇ. Berbeda dengan proporsi bobot udang, menjelaskan bahwa bobot udang terbesar didominasi pada kedalamaan 5-10 m yaitu sebesar 83,54 \% (Gambar 5). Adanya perbedaan proporsi jenis dan bobot hasil tangkapan pada udang ronggeng pada kisaran kedalaman berbeda kemungkinan disebabkan oleh sebaran populasinya yang cukup luas dan juga ditentukan oleh ketersediaan jumlah makanan udang ronggeng. Pada kedalaman 5-10 m proporsi jenis udang yang tertangkap sedikit, tetapi proporsi bobot udang ronggeng lebih besar. Kemungkinan pada saat penangkapan waktu penelitian, populasi udang ronggeng sedang beruaya menuju daerah perairan dangkal yang salinitasnya jauh lebih rendah.

Pada kedalaman 11-16 m proporsi jenis udang ronggeng lebih banyak tertangkap, akan tetapi proporsi terhadap keseluruhan lebih sedikit. Pada saat pengangkapan ada kemungkinan bahwa populasi udang tertangkap berukuran sama yaitu pada fase juvenil menuju dewasa. Udang ronggeng berukuran juvenil akan bermigrasi menuju perairan lebih dalam yang memiliki salinitas lebih tinggi.

\section{KESIMPULAN DAN SARAN}

\section{Kesimpulan}

Berdasarkan pembahasan hasil penelitian mengenai proporsi hasil tangkapan utama dan by catch menggunakan alat tangkap trammel net pada kedalaman berbeda maka dapat diambil simpulan sebagai berikut:

1. Berdasarkan total individu pada seluruh kedalaman, alat tangkap trammel net masih selektif digunakan, dengan jumlah individu hasil tangkapan utama lebih tinggi (57,15\%) dibandingkan dengan by-catch $(42,84 \%)$ dan total bobot hasil tangkapan dari trammel net didominasi oleh bycatch yaitu berupa jenis ikan (82\%), dibandingkan hasil tangkapan utama yaitu jenis udang (15\%) dan discard (3\%). 
2. Jenis udang peci, krosok, dogol dan udang kipas dominan pada kedalaman 5-10 m, sedangkan jenis udang jerbung, udang windu dan udang ronggeng dominan pada kedalaman 11-16 m.

\section{Saran}

1. Untuk penangkapan udang jerbung, udang windu, dan udang ronggeng sebaiknya diarahkan ke perairan yang lebih dalam (11-16 m), sedangkan untuk penangkapan udang peci, krosok, dogol dan udang kipas cukup di perairan dangkal (5-10 m).

2. Perlu adanya penelitian proporsi lanjutan mengenai analisis populasi udang untuk mengetahui kelimpahan udang pada Perairan Indramayu.

\section{DAFTAR PUSTAKA}

[BBPI] Balai Pengembangan Penangkapan Ikan. 2007. Pengoperasian Alat Tangkap Trawl yang dilengkapi dengan TED. Semarang (ID): BPPI.

Del Mundo CM. 2000. Philippine decapod crustacea. An illustrated handbook on the commercially important decapod crustacea of the Philippines Fisheries Resources Evaluation and Environmental Services Division, Bureau of Fisheries and Aquatic Resources. Quezon City, Philippines. 83 p.

[DKP] Dinas Perikanan Provinsi Jawa Barat. 2017. Buku Tahunan Perikanan Jawa Barat 2017. Bandung (ID): DKP Jabar.

Holthuis LB. 1980. Shrimps and prawns of the species of interest to fisheries. FAO Fish. Synop. 125(1):271.

Khaerudin A. 2006. Hasil Tangkapan Jaring Arad (Mini TrawI) yang Berbasis di Pesisir Utara, Kota Cirebon [skripsi]. Bogor (ID): Institut Pertanian Bogor.

Martosoedarmo B, Ranoemihardjo BS. 1980. Biologi Udang Penaeid. Budidaya Udang Penaeid. Jakarta (ID) : Direktorat Jendral Perikanan.

Moosa MK, Aswandy I. 1984. Udang Karang (Panulirus spp.) dari Perairan Indonesia. Proyek Studi Potensi Sumberdaya Alam Indonesia, Studi Potensi Sumberdaya Ikan. Jakarta (ID): LIPI.

Naamin N. 1984. Dinamika Populasi Udang Jerbung (Penaeus merguiensis de Man) di Perairan Arafura dan Alternatif Pengelolaannya [disertasi]. Bogor (ID): Institut Pertanian Bogor.

Odum EP. 1998. Dasar-Dasar Ekologi. 4rd edisi. Yogyakarta (ID): Gadjah Mada University Press.

Penn JW. 1981. A review of mark-recapture and recruitment studies on Australian Penaeid shrimp. Bull. Mar. Sci. 2: 227-247.

Pratiwi RD. 2008. Pelatihan Pembuatan Chitosan Dari Limbah Udang sebagai Bahan Pengawet Alami untuk Memperlama Daya Simpan pada Makanan di Kelurahan Pucangsawit. Surakarta (ID): Universitas Sebelas Maret.

Powers LW, Bliss DE. 1983. Terresterial Adaptations dalam The Biology Of Crustacea. New York (US): Academic Press.

Riyanto M. 2005. Pengoperasian Pukat Udang Pada Siang dan Malam Hari: Pengaruhnya Terhadap Hasil Tangkap Sampingan di Laut Arafura [skripsi]. Bogor (ID): Institut Pertanian Bogor.

Rizal A, Andriani Y, Kusumartono FXH. 2019. A Strategic Environmental Assessment for Southern Coastal of West Java Province, Indonesia. World Scientific News. 137:188-209

Rizal A. 2018. Reformulation of Regional Development Strategy To Strengthen Marine Sector in West Java, Indonesia. World Scientific News. 107:207-215. 
Rothschild BJYS, Brunenmeister L. 1984. Quantitative Assesment of Oceanic Squid by Means of Jigging Surveys. Biol. Oceanogr. 2:433-456

Setyono DED. 2006. Budidaya Pembesaran Udang Karang (Panulirus spp.). Oseana. 31(4): 39-48.

Steel RGD, Torrie JH. 1995. Prinsip dan Prosedur Statistika. Penterjemah Bambang Sumantri. Jakarta (ID): Gramedia Pustaka.

Subani W, Barus HR. 1989. Alat Penangkapan Ikan dan Udang laut di Indonesia. Jakarta (ID): Jurnal Penelitian Perikanan Laut.

Suman A, Rijal M, Manadiyanto. 1993. Jenis hubungan panjang berat, ukuran matang gonad dan potensi perikanan udang di Perairan Kutai Kalimantan Timur. Jurnal Perikanan Laut. 81:76-83.

Sunarto. 2002. Hubungan Intensitas Cahaya dan Nutrien dengan Produktivitas Primer Fitoplankton. Jurnal Akuatika. 2(1):24-28. 